\title{
A Novel Cross-Layer Network Architecture and Its Performance Analysis Using Mobile Ad Hoc Network Routing Protocol
}

\author{
Adarsh Kumar, Krishna Gopal, and Alok Aggarwal
}

\begin{abstract}
In this work a novel cross layer architecture is proposed for dynamic selection of routing protocol in Mobile Ad Hoc Network (MANET). Switching function is designed based on Quality of Service parameters and performance of proposed cross layer architecture is evaluated over quality of service parameters. Three routing protocols: Ad-Hoc On Demand Distance Vector (AODV), Destination Sequenced Distance Vector (DSDV) and Dynamic Source Routing (DSR) with variable number of nodes are used for performance analysis of proposed cross layer network architecture.
\end{abstract}

Index Terms-Cross layer architecture, H.323, MANET, performance evaluation, quality of service $(\mathrm{QoS})$, routing protocols, video streaming.

\section{INTRODUCTION}

Mobile Ad Hoc Networks (MANET) consists of fixed or mobile nodes which are connected through wireless and without the support of any fixed infrastructure or central administration. If two nodes are within each other's transmission range, then communication can be direct otherwise through intermediate nodes or relays (network). Nodes are self organized and can be deployed on anywhere. Nodes are free to move anywhere, anytime and at different speed. In a high mobility environment, the random and continued movement of nodes leads to a highly dynamic topology. These networks are characterized by scant capacity caused by the noise and interference inherent in wireless transmission. Some of the salient features of MANET are multi-path fading, limited battery, power of mobile devices, limited capacity, asymmetric/unidirectional links, rapid deployment, flexibility, robustness and highly dynamic network topology. MANETs can support advanced application links in civil application for sport events, audio/video conferencing, telemetric applications, military applications for group formation and movement of soldiers, tanks etc, in national situations for national crises, earthquakes, fires, floods, energy and rescue operations etc. for integration of cellular systems.

One of the greatest challenges in designing algorithms for MANET is providing Quality-of-Service (QoS) assurance [1]. Algorithms designed for MANET should be able to reserve

Manuscript received December 28, 2012; revised March 19, 2013.

Adarsh Kumar is with the Department of Computer Science and Information Technology, Jaypee National Institute of Information Technology, Noida, India (e-mail: adarsh.kumar@ jiit.ac.in).

Krishna Gopal is with Jaypee National Institute of Information Technology, Noida, India (e-mail: krishna.gopal@ jiit.ac.in).

Alok Aggarwal is with JP Institute of Engineering and Technology, Meerut, India (e-mail: alok289@yahoo.com). different network resources to achieve QoS requirements such as packet loss, throughput, delay, jitter and capacity etc.

In [2] a novel and complete tool set based on Evalvid framework for evaluating the delivered quality of MPEG video transmission in simulation of a network environment is presented. Tool set enables the investigation of the relationship between two popular objective metrics for QoS assessment of video quality delivery: the peak signal to noise ratio and the fraction of decodable frames. Publicly available real video traces have been used in previous studies [3] to evaluate their proposed network mechanism in a simulation environment. Using different performance metrics result has been presented like picture quality rating, packet/frame loss rate, packet/frame jitter, effective frame loss etc. Packet loss or jitter rate are network performance metrics. In [4] cognitive cross layer architecture has been proposed for the cognitive ad hoc network, where each node in the network can sense and learn from wireless environment, network environment and user's requirements and then it will respond the changes of environment by adapting system parameters and network services based on the learned results. In [1] performance evaluation of real time services over mobile as hoc networks using hierarchical and flat routing protocols has been done for reducing traffic overhead and showed that video quality got improved. A multi-path routing scheme for mobile ad hoc networks has been proposed in [5]. This extends the Ad hoc On-demand Multi-path Distance Vector (AOMDV) routing protocol by introducing a novel load balancing approach for concurrent distribution of traffic among multiple paths. Dynamic cross layer architectures have been proposed in [4]-[7]. All these work emphasize on the frameworks to enhance the multi-hop communication, reuse of channels by considering multiple disjoint paths and use of routing protocol without re-implementation. In [8] programming models have been used for wireless sensor network programming. This work suggests programming languages, tookits and platform for sensor network implementation. In order to implement MANET, in this work ns-2 platform is used with python language.

In this work, cross-layer architecture is proposed for improving the quality of video transmission based on network traffic, reliability and performance. Abstraction values of pixels at various layers are evaluated for calculating the performance of video transmission. Video distortion is calculated based on these abstraction values and further distortion is minimized by comparing the similar pixels. Mean squared error and distortion are the parameters used for performance evaluation. Further comparative network performance analysis of AODV (Ad hoc On-demand Distance Vector), DSDV (Destination Sequence Distance 
Vector) and DSR (Dynamic Source Routing) routing protocols has been done over 5/15/25/35/45 nodes.

This paper is organized as follows. Section 2 presents the proposed cross layer QoS architecture for improvement of QoS and QoS measurements. In section 3 comparative network performance analysis of AODV, DSDV and DSR routing protocols over 5/15/25/35/45 is presented. Lastly section 4 concludes the work presented.

\section{Proposed Cross Layer Quality of SERVICE ARCHITECTURE}

Proposed Cross Layer architecture shown in Fig. 1 provides a dynamic environment to change routing protocol based on QoS parameters. Routing protocols are mainly implemented in network layer. MAC to Network Layer cross layer proposed architecture enhancing the performance of network by reducing the overhead of Data Link Layer (DLL). QoS parameters are calculated from Physical and MAC layer and from these parameters routing protocol can be recommended to network layer. Switching Selection Function (SSF) is used to select a protocol. Switching Selection function is defined as:

$$
S S F=\sum_{i=1}^{3} F_{i}\left(\sum_{j=1}^{n} \bigodot_{\mathrm{j}}\right)
$$

where $F_{i}$ is a function of network parameter. This function is considered to be dependent on three network parameters: 1) Network Traffic, 2) Reliability and 3) Performance [9]. Further, Each network parameter function is dependent on network metric $(\odot)$.

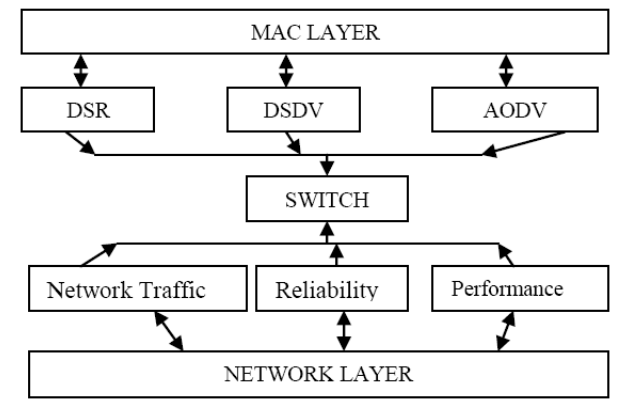

Fig. 1. Cross layer architecture

Network Traffic $\left(\mathrm{F}_{1}\right)$ is a function of throughput $\left(\odot_{1}\right)$, Packet drop rate $\left(\odot_{2}\right)$ and Packet Loss Rate $\left(\odot_{3}\right)$ [1]. Throughput is defined as the ratio of number of packets received at destination by number of packets sent from the source. Packet drop rate is the ratio of number of packets dropped per second. In this work, we calculated the number of packet dropped after regular intervals to measure the status of queue. Packets are dropped due to scarcity of bandwidth that thwart queue storage. Packet Loss rate is different from packet drop rate in terms of voltage fluctuation that prevent packet in proper delivery.

Reliability $\left(\mathrm{F}_{2}\right)$ is a function of Peak Information Rate (PIR) $\left(\odot_{1}\right)$ and Sustained Information Rate (SIR) $\left(\odot_{2}\right)$ [10]. These information rates are the maximum and minimum values of data rate after regular intervals respectively. At least minimum data rate is required for proper video communication. Calculation of SIR is an important measurement for video communication where as PIR can attract a customer for selection of any service parameter but it is difficult to maintain this rate throughout the agreement period.

Performance $\left(\mathrm{F}_{3}\right)$ is a function of maximum delay $\left(\odot_{1}\right)$, minimum delay $\left(\odot_{2}\right)$, maximum delay variation $\left(\odot_{3}\right)$, jitter $\left(\odot_{4}\right)$, coefficient of variation $\left(\odot_{5}\right)$, transmission delay $\left(\odot_{6}\right)$, propagation delay $\left(\odot_{7}\right)$, processing delay $\left(\odot_{8}\right)$ and end to end delay $\left(\odot_{9}\right)[10]$. Maximum and minimum are the time delay factors from whole network simulation time. Maximum delay variation is the largest value of how much $i^{\text {th }}$ packet delay varies from its average delay, i.e,

Maximumdelay=

Maximum(Average delay - delay for ith packet transmission

Network Jitter is directly proportionate to Maximum delay variation. Jitter is square root mean value of sum of all delays minus $i^{\text {th }}$ delay. As, network becomes congested, time to transmit a packet increases and in turn jitter value is also increases exponentially.

Jitter for ith packet $=\sqrt{\frac{(\text { Sum of all delays-ith delay) }}{\text { NumberofPackets }}}$

Next parameter is coefficient of variation, directly proportionate to jitter and thus delay variation.

$$
\text { Coefficient of Variation }(\mathrm{CoV})=\frac{\text { Jitter }}{\text { AverageDelay }}
$$

As jitter value increases with number of nodes and time. $\mathrm{CoV}$ increases proportionally.

$$
\begin{aligned}
& \text { End to End Delay }=\text { Processing Delay }+ \text { Propagation } \\
& \text { Delay }+ \text { Transmission Delay }
\end{aligned}
$$

where processing delay is the time taken at source node to process the packets to its next directly connected node, propagation delay is the time taken by intermediate network node to decide where to switch the packet and transmission delay is the time taken by network to transmit its packet from one node to its next node

\section{MAth COMPARATIVE NetwORK PERFORMANCE ANALYSIS}

A Different scenario have been generated for video transmission over 5/15/25/35/45 nodes on ns-2 [11], [9] simulator. Transmission range for nodes has been considered as 250 meters and all nodes can communicate in a $500 \times 100$ square meter area. Pause time to operate or transmit next packet is taken as $2 \mathrm{~ms}$. Nodes are uniformly distributed over the specific area. Radio propagation model is used for communication and an omni-directional antenna is considered. Any random node is considered as source and another as destination. At source node, video file is compressed using different encoder available then opened in 
binary read format. Different parameters related with video packets are calculated before transmission like: compression ratio, frame rates and format characteristics. Binary data is divided into fixed size segments. Transport and network layer protocol agents are used to transmit these fixed size segments over network. Encapsulation of intra (I), predicted (P) and bidirectional (B) frames is used to improve the video streaming. In these encapsulated packets, combination of intra, inter and bidirectional frames are done to improve the quality. At receiver side reverse process start, all packets are de-capsulated and information from these packets are extracted to generate video file Information from I, P and B frames are directed to generate best quality video. Intra frames (I) are used to represent the data portion. $\mathrm{P}$ and $\mathrm{B}$ frames can be generated from I frame. These frameworks are used for MPEG [2] and H.323. ITU's BT-500-11 standard [12]-[14] is applied for subjective measurement of video quality.

In this work network has been classified into three categories: small size network (5 nodes), medium size network (from 15 to 35 nodes) and large size network (45 nodes). However it can be extended beyond 45 nodes and till thousands. To analyze the performance of network, we tried to analyze the states of queues at regular intervals based on the concept that if number of packets en-queued is increasing with time then that network is considered as congested network. As time varies queues states are varying according to protocol used. For small scale networks AODV is giving better network performance than any other routing protocol whereas DSR protocol is considered to be overall better. Packets dropped are inversely proportionate to bandwidth available. As bandwidth availability increases, number of packet drop decreases.If bandwidth is kept constant for regular amount of time then number of drop packets and loss ratio increases exponentially with respect to. time in multimedia communication.

On Demand Routing protocol need time to establish a path thus at start of network for on demand protocols jitter is maximum and as time increases this value remains either constant or increases however for proactive routing protocols, it increases exponentially. Network performance analysis for Video Communication over 5/15/25/35/45 nodes is shown in tables 1 to 5 .

TABLE I: NUMBER OF PACKET EN-QUEUED FOR SMALL TO LARGE

\begin{tabular}{|c|c|c|c|c|c|c|}
\hline \multicolumn{7}{|c|}{ NETWORK } \\
\hline \multicolumn{2}{|l|}{ Nodes } & 5 & 15 & 25 & 35 & 45 \\
\hline $\begin{array}{l}\text { Parame } \\
\text { ter }\end{array}$ & Time & $\begin{array}{l}\text { DSR } \\
\text { /DSDV } \\
\text { /AODV }\end{array}$ & $\begin{array}{l}\text { DSR/ } \\
\text { DSD } \\
\text { V/ } \\
\text { AOD } \\
\text { V }\end{array}$ & $\begin{array}{l}\text { DSR/ } \\
\text { DSDV } \\
\text { /AOD } \\
\text { V }\end{array}$ & $\begin{array}{l}\text { DSR/ } \\
\text { DSDV } \\
\text { /AOD } \\
\text { V }\end{array}$ & $\begin{array}{l}\text { DSR/ } \\
\text { DSDV/ } \\
\text { AODV }\end{array}$ \\
\hline \multirow{3}{*}{$\begin{array}{l}\text { Numbe } \\
\text { r of } \\
\text { packet } \\
\text { En-Que } \\
\text { ued }\end{array}$} & $\begin{array}{l}10 \\
\text { sec }\end{array}$ & $5 / 6 / 3$ & $\begin{array}{l}25 / 30 \\
/ 18\end{array}$ & $\begin{array}{l}40 / 45 / \\
30\end{array}$ & $\begin{array}{l}50 / 66 / \\
38\end{array}$ & $\begin{array}{l}70 / 44 / \\
40\end{array}$ \\
\hline & $\begin{array}{l}50 \\
\sec \end{array}$ & $\begin{array}{l}100 / 80 / \\
40\end{array}$ & $\begin{array}{l}202 / 1 \\
88 / 10 \\
2\end{array}$ & $\begin{array}{l}300 / 20 \\
0 / 150\end{array}$ & $\begin{array}{l}430 / 3 \\
00 / 60 \\
0\end{array}$ & $\begin{array}{l}500 / 40 \\
0 / 690\end{array}$ \\
\hline & $\begin{array}{l}90 \\
\text { sec }\end{array}$ & $\begin{array}{l}300 / 25 \\
8 / 141\end{array}$ & $\begin{array}{l}300 / 2 \\
20 / 19 \\
0\end{array}$ & $\begin{array}{l}350 / 36 \\
0 / 500\end{array}$ & $\begin{array}{l}450 / 4 \\
20 / 80 \\
0\end{array}$ & $\begin{array}{l}430 / 54 \\
3 / 700\end{array}$ \\
\hline
\end{tabular}

Table I shows the comparative analysis of DSR, DSDV and AODV protocol in terms of packets en-queued at different nodes in a regular interval of time. Result shows that packet overhead is almost same for DSR, DSDV and AODV for small scale network for 10 seconds. Whereas for medium scale network packet overhead varies for three protocol and it is constant for DSDV protocol. At the end it is found that packet overhead is high for AODV and almost comparable for DSR and DSDV for large scale network depending upon the network scenario.

Table II shows the packet overhead for AODV for 5 and 45 nodes is higher results into more number of packets dropped. Thus AODV is having higher packet dropped ratio compare to DSDV and DSR. It is lowest for DSR. It is also found that at $10 \mathrm{sec}$ drop ratio is higher for AODV because AODV is an on-demand protocol and large numbers of packets are used for establishing the routes of the network.

Packet loss is different from packet drop, this is other than packet overhead and other factors may be fluctuation of signal, movement of node from one network to another, packet got corrupted, packet does not find its destination address etc. Packet loss is negligible for small scale network and higher for DSR protocol in large scale network. For medium scale network, it is almost same for DSDV and AODV protocols.

\begin{tabular}{|c|c|c|c|c|c|c|}
\hline Nodes & & 5 & 15 & 25 & 35 & 45 \\
\hline $\begin{array}{l}\text { Parame } \\
\text { ter }\end{array}$ & Time & $\begin{array}{l}\text { DSR } \\
\text { /DSDV/ } \\
\text { AODV }\end{array}$ & $\begin{array}{l}\text { DSR/ } \\
\text { DSDV } \\
/ \\
\text { AOD } \\
\text { V }\end{array}$ & $\begin{array}{l}\text { DSR/ } \\
\text { DSDV/ } \\
\text { AODV }\end{array}$ & $\begin{array}{l}\text { DSR/ } \\
\text { DSDV } \\
\text { /AOD } \\
\text { V }\end{array}$ & $\begin{array}{l}\text { DSR/ } \\
\text { DSDV/ } \\
\text { AODV }\end{array}$ \\
\hline $\begin{array}{l}\text { Numbe } \\
\text { r of } \\
\text { Drop } \\
\text { packets }\end{array}$ & $\begin{array}{l}100 \\
\text { sec }\end{array}$ & $0 / 0 / 0$ & $0 / 0 / 0$ & $1 / 3 / 5$ & $3 / 7 / 9$ & $\begin{array}{l}10 / 20 / \\
30\end{array}$ \\
\hline $\begin{array}{l}\text { \%age } \\
\text { Packet } \\
\text { Loss }\end{array}$ & $\begin{array}{l}100 \\
\text { sec }\end{array}$ & $\begin{array}{l}0 / 0 \\
/ 0 \%(\mathrm{al} \\
\text { most) }\end{array}$ & $\begin{array}{l}0 / 1 / \\
1 \% \\
\text { almost }\end{array}$ & $\begin{array}{l}1 / 3 / 3 \\
\%\end{array}$ & $\begin{array}{l}2 / 4 / 4 \\
\%\end{array}$ & $5 / 4 / 4 \%$ \\
\hline
\end{tabular}

Table III shows that the jitter is variation from average delay. Less the value of jitter more good is the protocol. For small, medium and large scale networks, DSR is better protocol as compare to AODV and DSDV. AODV is showing higher jitter value as compare to other protocols and for all types of networks.

\begin{tabular}{|c|c|c|c|c|c|c|}
\hline Nodes & & 5 & 15 & 25 & 35 & 45 \\
\hline $\begin{array}{l}\text { Param } \\
\text { eter }\end{array}$ & Time & $\begin{array}{l}\text { DSR } \\
\text { /DSDV/ } \\
\text { AODV }\end{array}$ & $\begin{array}{l}\text { DSR/ } \\
\text { DSDV/ } \\
\text { AODV }\end{array}$ & $\begin{array}{l}\text { DSR/ } \\
\text { DSDV/ } \\
\text { AODV }\end{array}$ & $\begin{array}{l}\text { DSR/ } \\
\text { DSDV/ } \\
\text { AODV }\end{array}$ & $\begin{array}{l}\text { DSR/ } \\
\text { DSDV/ } \\
\text { AODV }\end{array}$ \\
\hline Jitter & $\begin{array}{l}100 \\
\sec \end{array}$ & $\begin{array}{l}0.0387 / 0 \\
.1675 / 0 . \\
2310\end{array}$ & $\begin{array}{l}0.0487 / \\
0.176 / 0 \\
.349\end{array}$ & $\begin{array}{l}0.5671 / \\
0.765 / 0 \text {. } \\
771\end{array}$ & $\begin{array}{l}0.6895 \\
0 / 0.734 \\
/ 0.767\end{array}$ & $\begin{array}{l}0.4567 / \\
0.887 / 0 . \\
898\end{array}$ \\
\hline $\begin{array}{l}\text { Coeffic } \\
\text { ient of } \\
\text { Variati } \\
\text { on }\end{array}$ & $\begin{array}{l}100 \\
\text { sec }\end{array}$ & $\begin{array}{l}0.0002 / 0 \\
.0001 / 0 \\
0003\end{array}$ & $\begin{array}{l}0.0025 / \\
0.0120 / \\
0.0119\end{array}$ & $\begin{array}{l}0.0145 / \\
0.0180 / \\
0.0191\end{array}$ & $\begin{array}{l}0.0450 / \\
0.0484 / \\
0.0501\end{array}$ & $\begin{array}{l}0.01201 \\
/ 0.0544 \\
5 / 0.055 \\
44 \\
\end{array}$ \\
\hline \multirow{3}{*}{$\begin{array}{l}\text { Throug } \\
\text { hput of } \\
\text { Networ } \\
k\end{array}$} & $\begin{array}{l}\text { At } \\
\text { time } \\
10 \mathrm{sec}\end{array}$ & $\begin{array}{l}\text { 20/19/19 } \\
\text { Mpbs }\end{array}$ & $\begin{array}{l}\text { 10/10/9 } \\
\text { Mbps }\end{array}$ & $\begin{array}{l}\text { 12/10/1 } \\
2 \mathrm{Mbps}\end{array}$ & $\begin{array}{l}16 / 15 / 1 \\
6 \mathrm{Mbps}\end{array}$ & $\begin{array}{l}\text { 10/9/10 } \\
\text { Mbps }\end{array}$ \\
\hline & $\begin{array}{l}\text { At } \\
\text { time } \\
50 \mathrm{sec}\end{array}$ & $\begin{array}{l}\text { 10/9/9M } \\
\text { bps }\end{array}$ & $\begin{array}{l}\text { 10/10/ } \\
\text { 10Mbp } \\
\text { s }\end{array}$ & $\begin{array}{l}\text { 9/10/8 } \\
\text { Mbps }\end{array}$ & $\begin{array}{l}8 / 8 / 8 \\
\text { Mbps }\end{array}$ & $\begin{array}{l}7 / 6 / 6 \mathrm{M} \\
\mathrm{ps}\end{array}$ \\
\hline & $\begin{array}{l}\text { At } \\
\text { time } \\
100 \mathrm{se} \\
\mathrm{c}\end{array}$ & $\begin{array}{l}8 / 7 / 7 \mathrm{Mb} \\
\text { ps }\end{array}$ & $\begin{array}{l}8 / 8 / 8 \\
\text { Mbps }\end{array}$ & $\begin{array}{l}\text { 7/8/10 } \\
\text { Mbps }\end{array}$ & $\begin{array}{l}7 / 3 / 8 \\
\text { Mbps }\end{array}$ & $\begin{array}{l}\text { 6/8/6M } \\
\text { bps }\end{array}$ \\
\hline
\end{tabular}

Coefficient of variation is the root mean square value of jitter. More is the value of coefficient of variation less stable 
is the protocol. DSDV is showing higher values than other protocols for medium and large scale network. DSDV protocol is most stable protocol for the small scale networks.

Throughput of three protocols is same for small scale networks. For medium and large scale networks, throughput of DSDV protocol is higher as compare to other protocols. For small, medium and large scale networks, the initial value of throughput is much higher and it gradually decreases with increase of time. The reduction is more for small scale networks. Performance for small scale network reduces more for DSR and AODV as compare to DSDV protocol. This is shown in Table III.

Table IV shows that SIR for small and medium scale networks are higher for DSR whereas for large scale network it is higher for AODV protocol. Overall DSR can give better services to customer. PIR is good for DSR for small and medium scale network and it is best for AODV in large scale networks.

\begin{tabular}{|c|c|c|c|c|c|c|}
\hline \multicolumn{7}{|c|}{ TABLE IV: SIR } \\
\hline Nodes & & 5 & 15 & 25 & 35 & 45 \\
\hline $\begin{array}{l}\text { Para } \\
\text { meter }\end{array}$ & Time & $\begin{array}{l}\text { DSR } \\
\text { /DSDV/ } \\
\text { AODV }\end{array}$ & $\begin{array}{l}\text { DSR/ } \\
\text { DSDV/ } \\
\text { AODV }\end{array}$ & $\begin{array}{l}\text { DSR/ } \\
\text { DSDV/ } \\
\text { AODV }\end{array}$ & $\begin{array}{l}\text { DSR/ } \\
\text { DSDV/ } \\
\text { AODV }\end{array}$ & $\begin{array}{l}\text { DSR/ } \\
\text { DSDV/ } \\
\text { AODV }\end{array}$ \\
\hline \multirow{3}{*}{$\begin{array}{l}\text { SIR } \\
\text { for } \\
\text { transm } \\
\text { itting } \\
1 \mathrm{Mb} \\
\text { file }\end{array}$} & $\begin{array}{l}0^{\text {th }}- \\
10^{\text {th }} \\
\text { sec. }\end{array}$ & $\begin{array}{l}0.034 / 0 . \\
033 / 0.02 \\
2\end{array}$ & $\begin{array}{l}0.056 / \\
0.061 / \\
0.063\end{array}$ & $\begin{array}{l}0.071 / 0 \\
.075 / 0 \\
070\end{array}$ & $\begin{array}{l}0.080 / \\
0.061 / \\
0.035\end{array}$ & $\begin{array}{l}0.090 / 0 \\
1 / 0.023\end{array}$ \\
\hline & $\begin{array}{l}41^{\mathrm{st}}- \\
50^{\text {th }} \\
\text { sec. }\end{array}$ & $\begin{array}{l}0.056 / 0 . \\
055 / 0.04 \\
4\end{array}$ & $\begin{array}{l}0.067 / \\
0.063 / \\
0.061 \\
\end{array}$ & $\begin{array}{l}0.088 / 0 \\
.031 / 0 \\
066\end{array}$ & $\begin{array}{l}0.078 / \\
0.077 / \\
0.075 \\
\end{array}$ & $\begin{array}{l}0.101 / 0 \\
.100 / 0.0 \\
33 \\
\end{array}$ \\
\hline & $\begin{array}{l}91^{\text {st }}- \\
100^{\text {th }} \\
\text { sec. }\end{array}$ & $\begin{array}{l}0.080 / 0 . \\
079 / 0.66\end{array}$ & $\begin{array}{l}0.082 / \\
0.011 / \\
0.026\end{array}$ & $\begin{array}{l}0.085 / 0 \\
.022 / 0 . \\
031\end{array}$ & $\begin{array}{l}0.134 / \\
0.087 / \\
0.065\end{array}$ & $\begin{array}{l}0.234 / 0 \\
.231 / 0.5 \\
10\end{array}$ \\
\hline
\end{tabular}

TABLE V: DELAY VARIATION

\begin{tabular}{|c|c|c|c|c|c|}
\hline Nodes & 5 & 15 & 25 & 35 & 45 \\
\hline $\begin{array}{l}\text { Paramete } \\
\text { r }\end{array}$ & $\begin{array}{l}\text { DSR / } \\
\text { DSDV/ } \\
\text { AODV }\end{array}$ & $\begin{array}{l}\text { DSR/DS } \\
\text { DV/AOD } \\
\mathrm{V}\end{array}$ & $\begin{array}{l}\text { DSR/ } \\
\text { DSDV/ } \\
\text { AODV }\end{array}$ & $\begin{array}{l}\text { DSR/ } \\
\text { DSDV/ } \\
\text { AODV }\end{array}$ & $\begin{array}{l}\text { DSR/ } \\
\text { DSDV/ } \\
\text { AODV }\end{array}$ \\
\hline $\begin{array}{l}\text { Max } \\
\text { delay }\end{array}$ & $10 / 9 / 9 \mathrm{~ms}$ & $\begin{array}{l}\text { 20/19/19 } \\
\mathrm{ms}\end{array}$ & $\begin{array}{l}40 / 39 / 3 \\
9 \mathrm{~ms}\end{array}$ & $\begin{array}{l}40 / 40 / 4 \\
0 \mathrm{~ms}\end{array}$ & $\begin{array}{l}43 / 40 / 3 \\
0 \mathrm{~ms}\end{array}$ \\
\hline $\begin{array}{l}\text { Min } \\
\text { Delay }\end{array}$ & $1 / 1 / 1 \mathrm{~ms}$ & $2 / 1 / 1 \mathrm{~ms}$ & $\begin{array}{l}3 / 2 / 2 \\
\mathrm{~ms}\end{array}$ & $\begin{array}{l}2 / 3 / 2 \\
\mathrm{~ms}\end{array}$ & $\begin{array}{l}2 / 3 / 3 \\
\mathrm{~ms}\end{array}$ \\
\hline $\begin{array}{l}\text { Propagati } \\
\text { on Delay }\end{array}$ & $\begin{array}{l}0.345 / 0.1 \\
32.0 .268 \\
\mathrm{~ms}\end{array}$ & $\begin{array}{l}0.44 / 0.56 \\
/ 0.61 \mathrm{~ms}\end{array}$ & $\begin{array}{l}0.56 / 0.3 \\
2 / 0.44 \\
\mathrm{~ms} \\
\end{array}$ & $\begin{array}{l}0.678 / 0 . \\
78 / 1.00 \\
1 \mathrm{~ms}\end{array}$ & $\begin{array}{l}0.871 / 1 \\
100 / 1.6 \\
51 \mathrm{~ms} \\
\end{array}$ \\
\hline $\begin{array}{l}\text { Transmis } \\
\text { sion } \\
\text { Delay }\end{array}$ & $6 / 3 / 7 \mathrm{~ms}$ & $\begin{array}{l}7 / 6 / 8 \mathrm{mse} \\
\mathrm{c}\end{array}$ & $\begin{array}{l}10 / 11 / 1 \\
2 \mathrm{msec}\end{array}$ & $\begin{array}{l}11 / 12 / 1 \\
5 \mathrm{msec}\end{array}$ & $\begin{array}{l}13 / 15 / 1 \\
8 \mathrm{~ms}\end{array}$ \\
\hline $\begin{array}{l}\text { Processin } \\
\text { g Delay }\end{array}$ & $1 / 1 / 1 \mathrm{~ms}$ & $2 / 3 / 5 \mathrm{~ms}$ & $\begin{array}{l}5 / 6 / 6 \\
\mathrm{~ms}\end{array}$ & $\begin{array}{l}6 / 7 / 10 \\
\mathrm{~ms}\end{array}$ & $\begin{array}{l}8 / 18 / 20 \\
\mathrm{~ms}\end{array}$ \\
\hline $\begin{array}{l}\text { End to } \\
\text { End } \\
\text { Delay }\end{array}$ & $\begin{array}{l}7.345 / 4.1 \\
32 / 8.268 \\
\mathrm{~ms}\end{array}$ & $\begin{array}{l}9.44 / 8.56 \\
/ 13.61 \mathrm{~ms}\end{array}$ & $\begin{array}{l}15.56 / 1 \\
7.32 / 18 \\
44 \mathrm{~ms}\end{array}$ & $\begin{array}{l}17.678 / \\
19.78 / 2 \\
6.001 \\
\mathrm{~ms} \\
\end{array}$ & $\begin{array}{l}21.871 / \\
34.100 / \\
39.651 \\
\mathrm{~ms} \\
\end{array}$ \\
\hline
\end{tabular}

Table $\mathrm{V}$ shows the variation in end to end delay. For on-demand protocol the value of delays is higher at initial stage and for proactive protocols delay variation is highest for DSDV in large scale networks. Processing, transmission and propagation delay is higher for AODV protocol and is lowest for DSR protocol. Overall DSR protocol is having least delay thus better than any other protocol.

\section{CONCLUSION}

Performance of proposed architecture is evaluated over three routing protocols i.e. AODV, DSDV and DSR based on three QoS parameters: network traffic, reliability and performance for small to large scale networks. It is found that the proposed architecture improves the quality of video image however the improvement decreases with increase in number of nodes, i.e. for small scale network proposed architecture gives best results however for large scale network it gives comparatively less improvement. Maximum improvement is about $3 \%$ for 5 nodes however for 45 nodes it is about $1 \%$. Comparative network performance analysis of DSR/DSDV/ADOV over 5/15/25/35/45 nodes show that for all kind of network DSR performs best with respect to packet dropped and loss in the network. From throughput point of view DSR, AODV and DSDV performs best for small, medium and large scale network respectively.

\section{REFERENCES}

[1] P. Arce, J. C. Guerri, A. Pajares, and O. Larco "Performance evaluation of video streaming over ad hoc networks using flat and hierarchical routing protocols," Journal of Mobile Networks and Applications, 2008.

[2] C. H. Ke, C. K. Shieh, W. S. Hwang, and A. Ziviani, "An evaluation Framework for More Realistics Simulation of MPEG Video Transmission," Journal of Information Science and Engineering, pp. 425-440, 2008.

[3] P. Seeling, M. Reisslein, and B. Kulapla, "Network performance evaluation using frame size and quality traces of single-layer and two layer video: a tutorial," IEEE Comm. Surveys and Tutorials, vol. 6, pp. 58-78, 2004

[4] Y. Yong, W. Lifeng, and Y. Quan, "Cross Layer Architecture in Cognitive Ad Hoc Networks," IEEE CMC, vol. 2, pp. 47-51, 2009.

[5] L. Bononi and M. D. Felice, "Performance analysis of cross-layered multipath routing and MAC layer solutions for multi-hop ad hoc networks," ACM international workshop on Mobility management and wireless access, pp. 190-197, 2006.

[6] P. Janacik and T. Heimfarth, "Cross Layer Architecture of a Distributed OS for Ad Hoc Networks," IEEE International Conference on Autonomic and Autonomous Systems (ICAS'06), pp. 52, 2006.

[7] C. Cormio and K. R. Chowdhury, "Common control channel design for cognitive radio wireless ad hoc networks using adaptive frequency hopping," Elsevier Ad Hoc Netwokrs, pp. 430-438, 2010.

[8] R. Sugihara and R. K. Gupta, "Programming Models for Sensor Networks: A Survey," ACM Transaction on Sensor Networks, 2008.

[9] C. Lal, V. Laxmi, and M. S. Gaur, "Performance Analysis of MANET routing protocols for multimedia traffic," in Proc. International Conference on Computer and Communication Technology (ICCCT), pp. 595-600, 2011.

[10] H. Pucha, S. M. Das, and Y. C. Hu, "The performance impact of traffic patterns on routing protocols in Mobile Ad Hoc Networks," MSWiM $A C M$, pp. 211-219, venezia, Italy, 2004.

[11] The network simulator-ns-2. [Online]. Available: http://www.isi.edu/nsnam

[12] ITU-R BT.500-11: Methodology for the subjective assessment of the quality of television pictures, 2002.

[13] Ns-2 Tools and scripts. [Online]. Available: http://www.evanjones.ca/ns2.html/

[14] A. Szwabe, P. Misiorek, and P. Walkowiak, "IMS-based perforamnce analysis of a MANET controlled by the Delay-Aware NUM system," in Proc. IEEE Annual Wireless and Optical Communication Conference (WOCC), pp. 1-6, April 2011.

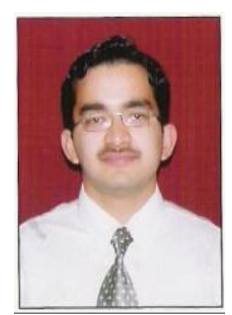

Adarsh Kumar is currently working as a senior lecturer of Computer Science and Information Technology Department at Jaypee Institute of Information Technology, Noida, INDIA, since September 2005. Mr. Kumar received his B.Tech (Computer Science) and M.Tech (Software Engineering) from Punjab Technical University and Thapar University, Patiala in June 2003 and July 2005 respectively. $\mathrm{He}$ is pursuing $\mathrm{PhD}$ in Computer Science from Jaypee Insttute of Information Technology, Noida, INDIA. 


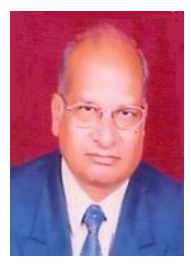

Krishna Gopal is currently working as Dean (Academic and Research) at Jaypee Institute of Information Technology, Noida, INDIA since 2012. Prof. Gopal is having 45 years of teaching and R\&D experience. . He received his Bachelor, Master and $\mathrm{PhD}$ in computer science and engineering from IIT, Madras, REC Kurukshetra in 1966, 1972, 1979 respectively. He published more than 100 papers in different journals,

conferences, patents etc. He handled six sponsored projects in his career. He has done various administrative responsibilities like: Director, Dean in REC Kurukshetra. He is achieved various awards like: Man of the year 1995 \& 2000 by American Bibliographical Institute, Listed in Marque's World Who's Who 2000, 2001, 2003 and member of various professional bodies like: Life Member System Society of India, Indian Society for Technical Education, Past Member Institution of Engineers (India), Indian Association for Quality and Reliability etc.
Alok Aggarwal is currently working as Director at JPIET, Meerut, INDIA, since 2010 .He is having work experience of fourteen years with a mix of software developer, research and teaching. He received his Bachelor, Master and $\mathrm{PhD}$ in computer science and engineering from kurukshetra university and IIT, Roorkee in 1995, 2001, 2010 respectively. He published three books and about forty research papers in different journals, conference proceedings etc. 